\title{
The drivers of antibiotic use and misuse: the development and investigation of a theory driven community measure
}

Mitchell K. Byrne ${ }^{1,2,6^{*}}$, Sebastien Miellet ${ }^{1,2,6}$, Anica McGlinn ${ }^{1}$, Janaye Fish ${ }^{2,3,6}$, Shahla Meedya ${ }^{2,4}$, Nina Reynolds ${ }^{2,7}$ and Antoine M. van Oijen ${ }^{2,5,6}$

\begin{abstract}
Background: Antimicrobial resistance is a global public health concern, with extensive associated health and economic implications. Actions to slow and contain the development of resistance are imperative. Despite the fact that overuse and misuse of antibiotics are highlighted as major contributing factors to this resistance, no sufficiently validated measures aiming to investigate the drivers behind consumer behaviour amongst the general population are available. The objective of this study was to develop and investigate the psychometric properties of an original, novel and multiple-item questionnaire, informed by the Theory of Planned Behaviour, to measure factors contributing to self-reported antibiotic use within the community.
\end{abstract}

Method: A three-phase process was employed, including literature review and item generation; expert panel review; and pre-test. Investigation of the questionnaire was subsequently conducted through a cross-sectional, anonymous survey. Orthogonal principal analysis with varimax rotation, cronbach alpha and linear mixed-effects modelling analyses were conducted. A 60 item questionnaire was produced encompassing demographics, social desirability, three constructs of the Theory of Planned Behaviour including: attitudes and beliefs; subjective norm; perceived behavioural control; behaviour; and a covariate - knowledge.

Results: Three hundred seventy-three participants completed the survey. Eighty participants (21\%) were excluded due to social desirability concerns, with data from the remaining 293 participants analysed. Results showed modest but acceptable levels of internal reliability, with high inter-item correlations within each construct. All four variables and the outcome variable of antibiotic use behaviour comprised four items with the exception of social norms, for which there were two items, producing a final 18 item questionnaire. Perceived behavioural control, social norms, the interaction between attitudes and beliefs and knowledge, and the presence of a healthcare worker in the family were all significant predictors of antibiotic use behaviour. All other predictors tested produced a nonsignificant relationship with the outcome variable of self-reported antibiotic use.

Conclusion: This study successfully developed and validated a novel tool which assesses factors influencing community antibiotic use and misuse. The questionnaire can be used to guide appropriate intervention strategies to reduce antibiotic misuse in the general population. Future research is required to assess the extent to which this tool can guide community-based intervention strategies.

Keywords: Antibiotic, Antibiotic use, Antimicrobial resistance, Attitude, Behaviour change, Social theory, Public health, Measurement, Psychometrics

\footnotetext{
* Correspondence: mbyrne@uow.edu.au

${ }^{1}$ School of Psychology, University of Wollongong, Building 41, Northfields

Ave, Wollongong, NSW 2522, Australia

Wollongong Antimicrobial Resistance Research Alliance (WARRA),

Wollongong, New South Wales, Australia

Full list of author information is available at the end of the article
}

(c) The Author(s). 2019 Open Access This article is distributed under the terms of the Creative Commons Attribution 4.0 International License (http://creativecommons.org/licenses/by/4.0/), which permits unrestricted use, distribution, and reproduction in any medium, provided you give appropriate credit to the original author(s) and the source, provide a link to the Creative Commons license, and indicate if changes were made. The Creative Commons Public Domain Dedication waiver (http://creativecommons.org/publicdomain/zero/1.0/) applies to the data made available in this article, unless otherwise stated. 


\section{Introduction}

Antibiotics are an antimicrobial agent defined as "a chemical substance produced by a microorganism that kills or inhibits the growth of another microorganism" [1]. Since the introduction of the first effective antimicrobial in 1937 [2], there has been persistent growth and spread of drugresistant bacteria, broadly referred to as antimicrobial resistance (AMR). AMR is defined as the phenomenon where infection-causing microorganisms, such as bacteria, have the ability to survive exposure to medicine which would normally inhibit their growth or kill them [3]. The health implications of AMR are extensive, affecting not only the treatment of a primary bacterial infection, but also the prophylactic use of antibiotics in routine surgical procedures, such as caesareans and hip replacements [3, 4]. O'Neill (2016) estimates that, unchecked, the growth of AMR will result in 10 million preventable deaths per year by 2050 . In addition to the human cost, the increase in AMR is associated with significant economic consequences [5]. AMR is associated with increased expenditure on health services, with greater resource utilisation and higher levels of routine health care costs [6-8]. The additional impact of AMR has downstream effects on health service productivity [9]. Unfettered, it is estimated that by 2050, AMR will have impacted world global production by \$US100 trillion [3].

From an evolutionary standpoint, AMR is unavoidable [10] due to bacteria's inherent ability to survive, mutate and adapt, following stress and greater exposure to antimicrobials [4]. Given that AMR cannot be reversed or eradicated [11], actions to slow and contain the development of resistance are imperative [12]. The rate of AMR development is widely understood to be facilitated by indiscriminate and unnecessary antibiotic use [3, 13-16]. The World Health Organisation (WHO) Global Strategy for Containment of Antimicrobial Resistance (2001) defines appropriate antimicrobial use as the "cost effective use of antimicrobials which maximises clinical therapeutic effect whilst minimising drug-related toxicity and development of antimicrobial resistance" [17].

Existing literature highlights consumer or patient demand and behaviour, as a driving force behind antibiotic misuse [18-20]. Understanding the extent of global trends in consumer demand for, and knowledge about, antibiotics is therefore an important component in the battle to curtail the growth of AMR and has precipitated multinational surveys. For example, a survey carried out by the Taylor Nelson Sofres (TNS) Opinion and Social for the European Commission (2010) gathered information from 26,761 individuals across the (then) 27 member states of the European Union. The survey found that $40 \%$ of respondents had taken antibiotics in the previous 12 months, with 95\% reporting that they (appropriately) obtained them from a medical practitioner. However, the survey also reported that only $20 \%$ of respondents were able to correctly answer four knowledge statements regarding antibiotics, including 53\% who believed that antibiotics kill viruses, and $47 \%$ who believed antibiotics were effective against colds and influenza. These results suggest that while Europeans report obtaining antibiotics through appropriate means (doctors), their intended use is often inappropriate [21].

A subsequent survey conducted by the WHO (2015) questioned 9772 individuals across two member states in the six WHO regions. In this survey it was found that $65 \%$ of respondents had used antibiotics in the previous 6 months, with $81 \%$ (range 56-93\%) indicating that they had obtained them from a medical professional. The WHO survey reported that $25 \%$ of respondents believed it acceptable to use antibiotics given to them by a friend or family member, $43 \%$ thought it acceptable to buy antibiotics or seek them from a doctor if they were sick with symptoms that they believed were effectively treated by antibiotics in the past, and 64\% incorrectly believed viruses such as colds and influenza could be treated by antibiotics [15].

According to Wise et al., (1998), 20\% of human antibiotic use occurs within the hospital sector, whilst $80 \%$ is within the community sector. Within this community portion, 20-50\% may be questionable and unnecessary [22]. Within Australia specifically, antibiotic consumption rate exceeds the Organisation for Economic Cooperation and Development (OECD) average [23]. Thus, an understanding of the drivers of Australian consumer antibiotic seeking and use is warranted.

Both the TNS Opinion \& Social (2010) and WHO (2015) surveys had numerous limitations, including various sampling techniques, bias toward more educated responders, and an absence of checks upon socially desirable responding. Furthermore, neither survey was theory informed in order to enable prediction of consumer antibiotic use, other than the potential impact of poor knowledge about antibiotics and AMR, and neither reported detailed psychometric properties of the questionnaires. They do, however, confirm previous research which has identified a range of key factors contributing to patient behaviour with respect to antibiotic use, including attitudes and beliefs, subjective norms, self-efficacy and knowledge [6, 24].

There are few measures which currently exist in this area. Many are specific to population sub-groups, including physicians, parents [6, 25-27], medical students [28] and pharmacists [29, 30]. To our knowledge, there exists no sufficiently validated measure which aims to investigate factors influencing antibiotic use within the general populace [31].

The current study sought to develop a questionnaire that predicts the factors influencing a consumer's intentions to indiscriminately obtain and use antibiotics. Given that attitudes and beliefs [32], the opinions of 
others within a person's social or professional network [33-35], and the self-perceived (and actual) ability to obtain antibiotics [36-38] have all been independently associated with the use of antibiotics, the current study aimed to construct a questionnaire informed by the Theory of Planned Behaviour (TpB) [39], a respected and highly cited model which predicts health related behaviours [40-43]. The TpB, which has yet to be used in the context of antibiotic use for consumers, would suggest that a person's actual use of antibiotics is best predicted by their intentions, which are influenced by three major components (see Fig. 1): (a) attitudes, referring to one's positive or negative evaluation of indiscriminate antibiotic use, (e.g. 'the negatives of taking antibiotics outweigh the positives'); (b) subjective norm, involving their perception of the social expectations of indiscriminate antibiotic use, (e.g. 'my friends and family would follow recommendations for antibiotic use'); and (c) perceived behavioural control (PBC), reflecting the beliefs regarding the ease or difficulty in accessing antibiotics, (e.g. 'I would easily be able to get antibiotics if I wanted them'). $\mathrm{PBC}$ was the only control measure as actual behavioural control (added to later TpB models) [44] was unable to be measured within this study protocol. A condition of the strength of this $\mathrm{PBC}$-behaviour relationship is that 'perceptions of behavioural control must reflect actual control in the situation with some degree of accuracy'. When perceptions of control are accurate, $\mathrm{PBC}$ is expected to predict behaviour [45-47].

One of the most extensive TpB reviews, focusing on prospective behaviours across 237 studies, was conducted by McEachan, Conner, Taylor and Lawton, [48], who found that the $\mathrm{TpB}$ could explain $19.3 \%$ of variance in behaviour and $44.3 \%$ of the variance in intention to behave. McEachan and colleagues further demonstrated that the $\mathrm{TpB}$ provides strong predictions of intention and behaviour across a range of health behaviours, with the attitude component being the strongest behavioural intention predictor. Further, Ajzen, (1991) suggests that the $\mathrm{TpB}$ is highly adaptive, possessing the ability to incorporate additional predictors where required, providing that they maintain the ability to capture a significant proportion of variance in intention or behaviour, and also given that the initial variables have been considered. Given previous research, knowledge about antimicrobials, and AMR specifically, would be expected to influence attitudes [32].

Limitations surrounding the $\mathrm{TpB}$ include its sole reliance upon self-reported behaviour, potentially inspiring socially desirable and less accurate predictions of objective behaviour [47]. Armitage and Conner undertook a meta-analysis of 161 articles containing 185 independent empirical tests of the $\mathrm{TpB}$, concluding that the use of the model is effective in predicting intention and behaviour, more so in the context of subjective self-reported behaviour over observed behaviour (Rsquared 0.31 and 0.20 respective) [40]. This is not a limitation specific to the $\mathrm{TpB}$, but broadly to the area of social psychology, and is not a large cause for concern given the model still capably measures a good amount of variance in prospective measures of actual behaviour [40]. Moreover, the $\mathrm{TpB}$ showcases high consistency between intention and behaviour, even in contexts of differing emotional states [47]. None-theless, attention to social desirability would enhance the predictive validity of the $\mathrm{TpB}$ as applied to consumer antibiotic use.

Thus, the aim of the current study is to develop and investigate the psychometric properties of an original, novel and multiple-item quantitative questionnaire, aiming to identify factors contributing to antibiotic use within the community, informed by the TpB. Considering the adaptive nature of the $\mathrm{TpB}$ [39], knowledge was added as a variable of interest within the current study, due to the array of literature which indicates a relationship between knowledge and antibiotic-use behaviour [31].

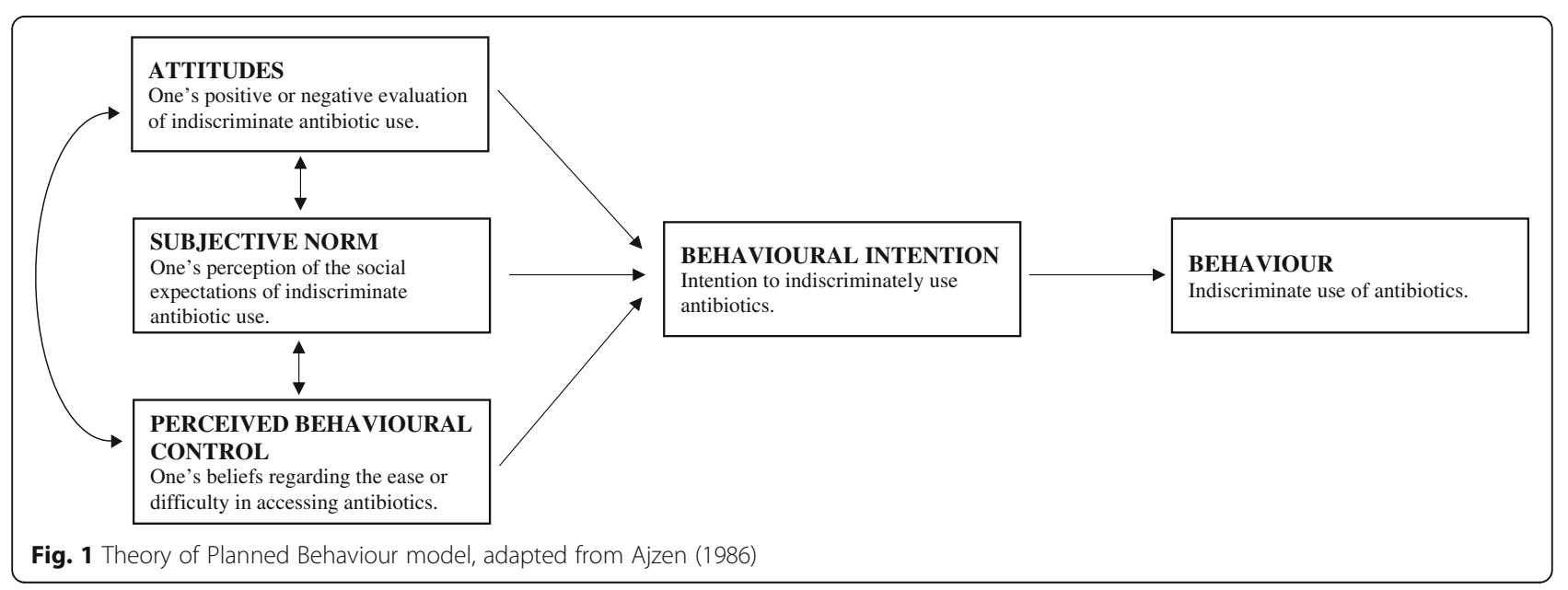




\section{Methods}

\section{Questionnaire development}

A three-phase process was employed to develop the Antibiotic Use Questionnaire (AUQ) utilised within this study. Phases included: a literature review and item generation; expert panel review; and pre-test. Investigation of the AUQ was then subsequently conducted through a cross-sectional, anonymous and voluntary survey.

\section{Phase one. Literature review and item generation}

An opening list of 43 items were drawn from a literature review of previous studies investigating consumer characteristics and self-reported antibiotic use, using search terms such as 'antibiotic use', 'AMR', and 'antibiotic use influences'. Questions were then grouped under discrete categories, including demographics, knowledge, TpB constructs (attitude, subjective norm and $\mathrm{PBC}$ ), and an outcome factor self-reported antibiotic use behaviour. Items were adapted where required to suit the cultural and sociodemographic context of the target population. For example, 'Aboriginal or Torres Strait Islander' was added as an option for ancestry to reflect the Australian population.

\section{Phase two. Expert panel review}

The original 43 item questionnaire was examined for content validity by a panel of eight experts, organised to represent a range of fields including psychology, business and health. Questions were evaluated with respect to the extent to which, on face value, they aligned with the TpB variables (including knowledge), their repetition, clarity and cultural relevance. Additional questions were generated in areas under-represented, such as social norms, and redundant questions removed. A subset of six items from the Marlowe-Crowne Social Desirability Scale [49] were randomly selected and incorporated into the questionnaire, to allow for measurement of the honesty and reliability in respondent answers. Following agreement by the expert panel on the established questions, selected items (excluding demographics) were randomised using Stat Trek: Random Number Generator (no date) to mediate response bias. Review of the questionnaire involved 10 iterations with the expert panel and yielded an initial (preassessment) questionnaire of 60 items, organised as per Table 1, with questions requiring multiple choice, dichotomous or likert scaled responses.

\section{Phase three. Pre-test}

Before administration of the questionnaire to participants, a group of 10 participants pre-tested the survey to examine face validity. Feedback was gathered on time to completion, question clarity, perceived relevance, and face validity. Minor adjustments were made based on feedback received.

Table 1 Organisation of the initial (pre-assessment) AUQ

\begin{tabular}{|c|c|c|c|}
\hline Variable & Description & Instrument Items & Example \\
\hline Demographics & Data relating to the characteristics of a participant. & 12 items & $\begin{array}{l}\text { 'Are you trained in a health-related field?' } \\
\text { 'How often have you used antibiotics } \\
\text { within the past month?' }\end{array}$ \\
\hline Social Desirability & $\begin{array}{l}\text { A participant's tendency to respond in a } \\
\text { way they deem more socially acceptable, } \\
\text { than their 'true' response. }\end{array}$ & 6 items & $\begin{array}{l}\text { 'I have never deliberately said something } \\
\text { that hurt someone's feelings' } \\
\text { 'There have been times when I was quite } \\
\text { jealous of the good fortune of others' }\end{array}$ \\
\hline
\end{tabular}

TpB Construct

Attitude and Beliefs

The degree to which a participant has a positive or negative evaluation of indiscriminate antibiotic use.

Subjective Norm

A participant's belief about whether significant others would approve or disapprove of indiscriminate antibiotic use.

Perceived Behavioural Control A participants beliefs regarding the ease or difficulty in assessing antibiotics.

Knowledge $^{*}$

Behaviour
A participants understanding and awareness regarding indiscriminate antibiotic use and AMR.

Self-reported antibiotic use behaviour.
13 items

4 items

5 items

10 items

10 items

\section{'It is my right to ask for an antibiotic from my doctor' \\ 'I trust my doctor when they tell me I do not require antibiotics' \\ 'My friends and family only use antibiotics when prescribed' \\ 'Most people I know keep leftover antibiotics' \\ I would change doctors if my doctor did not prescribe antibiotics when I wanted them' 'I feel confident to ask for antibiotics when I need them' \\ 'I could easily get antibiotics online' \\ 'Antibiotics will reduce my cold symptoms' 'Antibiotics are less likely to work in the future' 'The same antibiotic will work in the treatment of the same infection in the future' \\ 'I obtain antibiotics without a prescription' I would take antibiotics without consulting a doctor' \\ 'I use leftover or unused antibiotics or scripts'}




\section{Data collection and ethics}

The finalised questionnaire was distributed via an anonymous cross-sectional survey conducted between July August 2018. Tacit consent was obtained, inferred through anonymous completion and return of the questionnaire. Survey Monkey was used to create a soft copy version of the questionnaire, with the link being distributed via nonmoderated e-mail services and social media, predominantly incorporating snowballing techniques. Hard copy questionnaires were also distributed, mainly to participants who were unable to be reached via e-mail or social media, and for the purposes of purposive sampling after a middata collection review identified disparities in demographic representation. All hard copy questionnaires were completed in the presence of a researcher. Purposive sampling took place in popular public spaces, including a local shopping mall and retirement club, with a desire to achieve balance from older age groups, males, and those of lower socioeconomic status and education level. Hardcopies were returned directly to the researcher after completion, and manually entered into a Microsoft Office Excel, Version 10, spread sheet. The current study was approved by the Health and Medical Human Research Ethics Committee (Joint University of Wollongong and Illawarra Shoalhaven Local Health District, 2018/330).

\section{Sample}

All recipients of the questionnaire, aged 18 years and over, were invited to partake in the research. Completed questionnaires were received from 373 participants. The majority of participants were recruited via online platforms $(91 \%, n=338)$, with the remaining participants recruited in person $(9 \%, n=34)$. Eighty participants $(21 \%)$ were excluded from the analysis, due to concerns regarding the accuracy and reliability of their responses, after scoring equal to or higher than five in social desirability. Data from the remaining 293 (79\%) participants was analysed.

\section{Data analysis}

Data analysis was carried out using Matlab R2018A (The MathWorks Inc). All completed questionnaires were screened for missing data, outliers and coding errors. Participants answered at least $83 \%$ of the questions (mean = 99.24\%, standard deviation (SD) =3.23). Descriptive statistics for patient demographics were reported, expressed as raw numbers and percentages. An orthogonal principal component analysis with varimax rotation (factoran Matlab function) was utilised to assess the factor loadings of the questionnaire items for the four dimensions of the $\mathrm{TpB}$ and the covariate - knowledge. Cronbach alpha was used to determine the internal reliability of items relating to each of the five factors. Furthermore, linear mixed-effects modelling was employed to study the influence of the $\mathrm{TpB}$ factors on intended antibiotic use behaviour. The moderation from knowledge on the link between attitude/belief and intended behaviour was modelled as an interaction term between knowledge and attitude/belief. The fixed effects of the model included the interaction between attitudes and beliefs, and knowledge, $\mathrm{PBC}$, social norms, age, gender, education, whether the participants had children, health trained, health worker in the family, frequency of antibiotic consumption, financial security, and most recent antibiotic consumption. The random effect was the participants.

\section{Results}

Participant demographics are reported in Table 2. Mean score for social desirability (range 0 to 6 ) was 2.69 ( \pm 1.16). Of the $80(21 \%)$ participants who were excluded due to a high social desirability score ( 5 or above), $65 \%$ $(n=52)$ were female with $55 \%(n=44)$ of respondents having a bachelor degree qualification or higher. 59\% $(n=47)$ of respondents were aged between 18 and 44 years, with the 18-24 year category the highest $(n=25)$. Whilst majority of respondents were not personally trained in a health-related field $(68 \%, n=54), 58 \%(n=$ 46) had a family member or friend with a health-related occupation. $55 \%(n=44)$ of respondents excluded had not taken an antibiotic within the past year.

Of the remaining 293 participants whose data was included, majority $(74 \%, n=217)$ identified themselves as infrequent antibiotic users, consuming antibiotics once a year or less, with less than a third of respondents $(30 \%, n=87)$ consuming antibiotics within the past 6 months. Consistent with previous research, although $83 \%(n=242)$ of participants correctly identified that antibiotics should be used for the treatment of bacterial infections, 25\% $(n=74)$ of these respondents also incorrectly identified that they work for viral infections and/or fungal infections.

Factor loadings of the questionnaire items for the three variables of the $\mathrm{TpB}$, the outcome variable (behaviour), and covariate, knowledge, are reported in Table 3. All five variables encompassed four items with the exception of social norms, which included two items, yielding a final 18-item questionnaire.

Results showed modest but acceptable levels of internal reliability (Cronbach alpha) within each variable: attitudes and beliefs $=0.60$; social norms $=0.59$; $\mathrm{PBC}=0.64$; knowledge $=0.61$; behaviour $=0.76$ [50]. Inter-item correlations where high within each variable (Attitudes and beliefs $=$ 0.28 ; social norms $=0.42 ; \mathrm{PBC}=0.30$; knowledge $=0.28$; behaviour $=0.45)$. In contrast, inter-item correlations were low between variables ( 0.11 on average).

A Linear-mixed model was run with the following fixed effects: the interaction between attitudes and beliefs and knowledge; PBC; social norms; age; gender; education; whether the participants had children, were 
Table 2 Participant characteristics

\begin{tabular}{|c|c|c|}
\hline Characteristic & $n^{*}$ & $\%$ \\
\hline \multicolumn{3}{|l|}{ Age } \\
\hline $18-24$ & 124 & $42.5 \%$ \\
\hline $25-34$ & 49 & $16.8 \%$ \\
\hline $35-44$ & 28 & $9.6 \%$ \\
\hline $45-54$ & 32 & $11.0 \%$ \\
\hline $55-64$ & 34 & $11.6 \%$ \\
\hline $65-74$ & 9 & $3.1 \%$ \\
\hline $75+$ & 16 & $5.5 \%$ \\
\hline \multicolumn{3}{|l|}{ Gender } \\
\hline Male & 106 & $36.2 \%$ \\
\hline Female & 186 & $63.5 \%$ \\
\hline Other & 1 & $0.3 \%$ \\
\hline \multicolumn{3}{|l|}{ Ancestry ${ }^{\#}$} \\
\hline Australian & 190 & $64.8 \%$ \\
\hline Aboriginal or Torres Strait Islander & 8 & $2.7 \%$ \\
\hline Chinese & 11 & $3.8 \%$ \\
\hline English & 77 & $26.3 \%$ \\
\hline German & 17 & $5.8 \%$ \\
\hline Irish & 29 & $9.9 \%$ \\
\hline Italian & 9 & $3.1 \%$ \\
\hline Scottish & 26 & $8.9 \%$ \\
\hline Other & 66 & $22.5 \%$ \\
\hline \multicolumn{3}{|l|}{ Education level } \\
\hline Secondary School, did not complete year 12 & 17 & $5.8 \%$ \\
\hline Secondary School, completed year 12 & 59 & $20.1 \%$ \\
\hline TAFE & 47 & $16.0 \%$ \\
\hline Bachelor's Degree & 125 & $42.7 \%$ \\
\hline Postgraduate Degree, i.e. Masters or PhD & 45 & $15.4 \%$ \\
\hline \multicolumn{3}{|l|}{ Whether Participants had Children } \\
\hline Yes & 104 & $35.5 \%$ \\
\hline No & 189 & $64.5 \%$ \\
\hline \multicolumn{3}{|l|}{ Financial security } \\
\hline Strongly Disagree & 13 & $4.4 \%$ \\
\hline Disagree & 45 & $15.4 \%$ \\
\hline Agree & 180 & $61.4 \%$ \\
\hline Strongly Agree & 55 & $18.8 \%$ \\
\hline \multicolumn{3}{|l|}{ Personal training in a health-related field } \\
\hline Yes & 87 & $29.7 \%$ \\
\hline No & 206 & $70.3 \%$ \\
\hline \multicolumn{3}{|c|}{ Family member or friend with a health-related occupation } \\
\hline Yes & 178 & $61.0 \%$ \\
\hline No & 114 & $39.0 \%$ \\
\hline
\end{tabular}

*Number may not add up to 293 due to missing values. "Multiple responses allowed health trained, had a health worker in the family; frequency of antibiotic consumption; financial security; and most recent antibiotic consumption. The random effect was the participants. Fixed effects coefficients can be found in Table 4. For this model the Akaike Information Criterion (AIC) was 1033.5 and the Bayesian Information Criterion (BIC) was 1088.7. The ordinary R-squared was 0.7071 and the adjusted R-squared was 0.6945 ; indicating that this model explains around $70 \%$ of the variance in the self-reported antibiotic misuse. The part of variance explained by the model decreases when knowledge is not included (ordinary R-squared: 0.6950; adjusted R-squared: 0.6820 ). The modest decrease could be explained by the other fixed effects capturing partially the part of variance that was explained by knowledge; thus indicating some relative overlap between these constructs as illustrated by the loading factors in the factor analysis. The fixed effect variables, $\mathrm{PBC}(\beta=-.22$, $p=0.001)$, Social Norms $(\beta=.24, p=0.047)$, interaction between attitudes and beliefs and knowledge $(\beta=.09$, $p=<0.001)$, and the presence of a healthcare worker in the family $(\beta=.35, p=0.039)$, were all significant predictors of antibiotic use behaviour. All other predictors tested did not produce a significant relationship with the outcome variable.

An alternative model was tested with the same variables except for the moderator knowledge. AIC and BIC were slightly higher in this case (1040.9 and 1096.1 respectively) and the model explained a smaller proportion of variance (ordinary and adjusted Rsquared: 0.6950 and 0.6820 ).

Scores for rational antibiotic use were calculated using the factor loading coefficients from the questionnaire items which loaded to the construct of behaviour. Calculations were made as follows: $0.561 *$ Behaviour Item $5+0.83 * \mathrm{Be}$ haviour Item 6-0.544*Behaviour Item $13+0.602$ *Behaviour Item 14. Scores were subsequently normalised in order to have 0 as the minimal score, and 10 as the maximum score. High scores are reflective of rational antibiotic use, whilst low scores are reflective of less rational behaviour. Figure 2 outlines scores of rational antibiotic use for all participants.

\section{Discussion}

The aim of the present study was to develop and investigate a novel quantitative measure, modelled on the TpB. The study sought to assess the factors influencing community antibiotic use and misuse, including: $\mathrm{TpB}$ variables (attitudes and beliefs, subjective norm and $\mathrm{PBC}$ ); knowledge; and key demographic characteristics (such as age, gender, education level, financial status, the presence of offspring and personal health-related field training). 
Table 3 Factor loadings for questionnaire items*

\begin{tabular}{|c|c|c|c|c|c|}
\hline Item Number and Item & Attitude and Beliefs & Social Norms & PBC & Knowledge & Behaviour \\
\hline Item 1. Antibiotics will reduce my cold symptoms & 0.138 & 0.093 & 0.136 & 0.769 & 0.044 \\
\hline Item 2. My friends and family follow recommendations for antibiotic use & -0.036 & 0.552 & -0.052 & 0.121 & 0.016 \\
\hline Item 3. Antibiotics are needed for the common cold & 0.081 & 0.029 & -0.001 & 0.695 & 0.050 \\
\hline Item 4. Antibiotics may have negative side effects & 0.137 & 0.282 & -0.089 & -0.294 & -0.013 \\
\hline Item 5. I would take antibiotics without consulting a doctor & 0.295 & -0.191 & 0.195 & 0.090 & 0.561 \\
\hline Item 6. I use leftover or unused antibiotics or scripts & 0.149 & 0.032 & 0.110 & 0.090 & 0.830 \\
\hline Item 7. It is my right to ask for an antibiotic from my doctor & 0.423 & 0.079 & -0.019 & 0.158 & 0.071 \\
\hline Item 8. My friends and family only use antibiotics when prescribed & -0.010 & 0.698 & -0.185 & 0.006 & -0.151 \\
\hline Item 9. I know I need antibiotics before I see my doctor & 0.693 & 0.003 & 0.000 & -0.082 & 0.231 \\
\hline $\begin{array}{l}\text { Item } 10 \text {. In my community, it is common to use antibiotics without } \\
\text { a prescription }\end{array}$ & -0.044 & -0.255 & 0.390 & 0.075 & 0.119 \\
\hline Item 11. I feel confident to ask for antibiotics when I need them & 0.505 & 0.004 & 0.155 & -0.054 & 0.075 \\
\hline Item 12. Antibiotics are less likely to work in the future & 0.011 & -0.002 & 0.027 & -0.410 & -0.093 \\
\hline Item 13. I consult with my doctor prior to taking antibiotics & -0.082 & 0.338 & -0.009 & -0.217 & -0.544 \\
\hline Item 14. I keep leftover or unused antibiotics or scripts & 0.187 & 0.040 & 0.078 & 0.008 & 0.602 \\
\hline Item 15. I could easily get antibiotics from a doctor & 0.303 & -0.043 & 0.358 & -0.018 & 0.029 \\
\hline Item 16. I could easily get antibiotics online & 0.071 & -0.038 & 0.517 & 0.037 & 0.011 \\
\hline Item 17. I could easily get antibiotics from my family / a friend / household & 0.037 & -0.106 & 0.884 & 0.010 & 0.191 \\
\hline $\begin{array}{l}\text { Item } 18 \text {. By the time I am sick enough to see my doctor, I expect a } \\
\text { prescription of antibiotics }\end{array}$ & 0.408 & -0.108 & 0.037 & 0.131 & 0.226 \\
\hline
\end{tabular}

*Bold font indicates which factor the items are associated with

The confirmatory factor analysis identified items corresponding to the three variables of the $\mathrm{TpB}$, the outcome variable (behaviour), and the covariate knowledge. The selected items demonstrated good psychometric properties in terms of internal reliability and convergent and discriminant validity. The internal reliability values are particularly encouraging considering the small number of items and the fact that when utilising Cronbach's
Alpha as a measure of internal consistency, the greater the number of items in the pool, the better the chance of obtaining a positive value, indicating greater internal consistency [51].

A linear-mixed effects analysis revealed that intent of antibiotic use behaviour can significantly be explained by each of the TpB variables (PBC, social norms and attitudes and beliefs moderated by knowledge) and that the $\mathrm{TpB}$

Table 4 Fixed effects coefficients

\begin{tabular}{|c|c|c|c|c|c|c|c|}
\hline Name & Estimate & Standard Error & t-Statistic & Degrees of Freedom & $p$-Value & Lower & Upper \\
\hline Intercept & 2.404 & 1.090 & 2.206 & 280 & 0.028 & 0.259 & 4.548 \\
\hline Interaction between attitudes, beliefs and knowledge & 0.088 & 0.013 & 6.813 & 280 & $5.834 \mathrm{e}-11$ & 0.062 & 0.113 \\
\hline Perceived behavioural control & -0.220 & 0.067 & -3.298 & 280 & 0.001 & -0.351 & -0.089 \\
\hline Social norms & 0.243 & 0.122 & 1.991 & 280 & 0.048 & 0.003 & 0.483 \\
\hline Age & -0.012 & 0.067 & -0.176 & 280 & 0.861 & -0.143 & 0.119 \\
\hline Gender & -0.177 & 0.177 & -1.005 & 280 & 0.316 & -0.525 & 0.170 \\
\hline Education level & 0.020 & 0.073 & 0.269 & 280 & 0.788 & -0.124 & 0.163 \\
\hline Whether participants had children & 0.126 & 0.234 & 0.539 & 280 & 0.590 & -0.334 & 0.586 \\
\hline Personal training in a health-related field & -0.126 & 0.184 & -0.688 & 280 & 0.492 & -0.488 & 0.235 \\
\hline Family member or friend with a health-related occupation & 0.346 & 0.167 & 2.079 & 280 & 0.039 & 0.018 & 0.674 \\
\hline Frequency of antibiotic use & 0.132 & 0.092 & 1.435 & 280 & 0.152 & -0.049 & 0.313 \\
\hline Perception of financial security & -0.011 & 0.120 & -0.092 & 280 & 0.927 & -0.247 & 0.225 \\
\hline Last occasion of antibiotic use & 0.074 & 0.086 & 0.855 & 280 & 0.393 & -0.096 & 0.244 \\
\hline
\end{tabular}




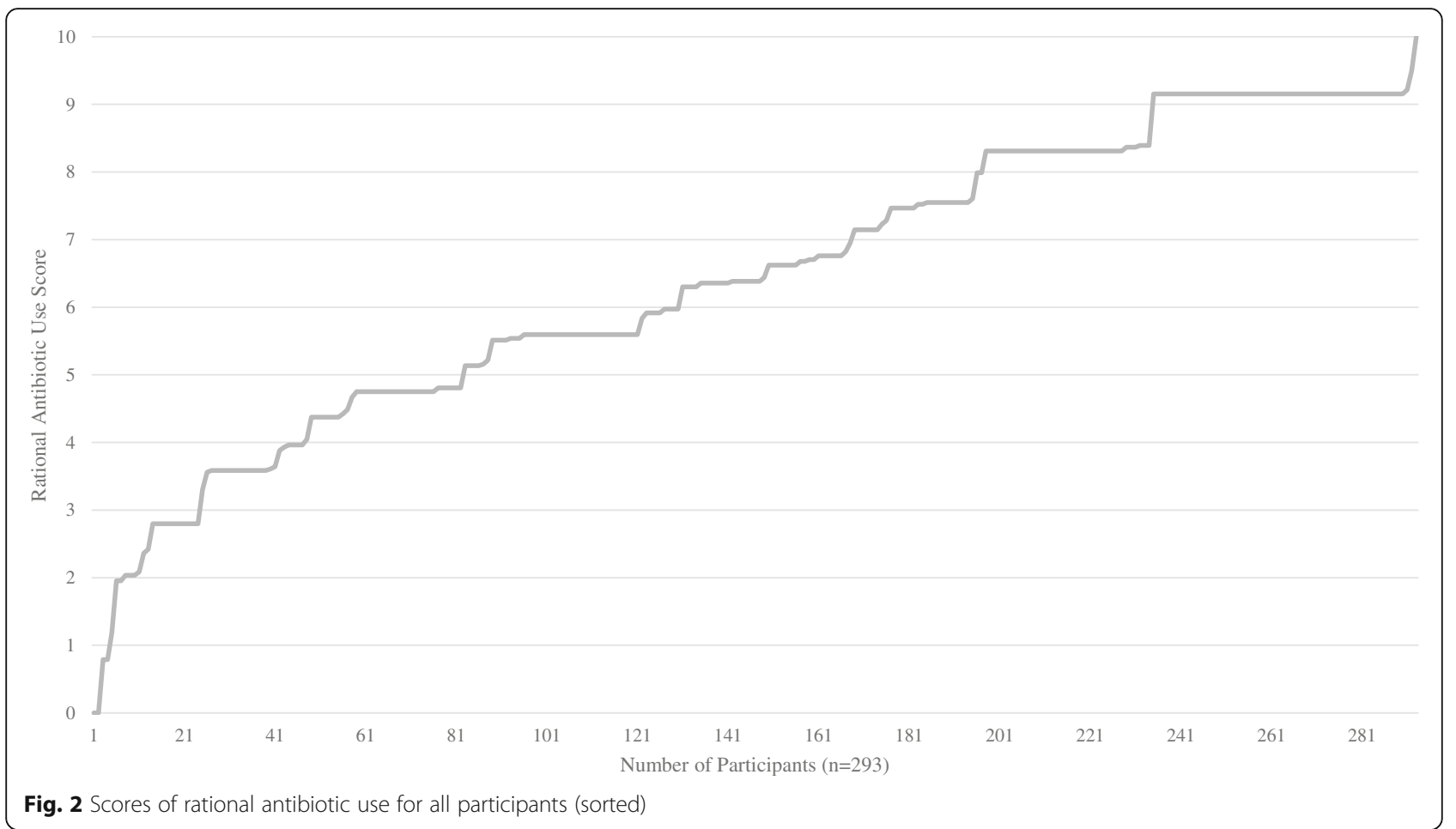

construct predicted $70 \%$ of the variance in antibiotic use and misuse. This amount of predicted variance exceeds that of past literature using the $\mathrm{TpB}$ model to predict health related behaviours [39-41, 48], and supports the use of the TpB model in this context. The presence of a healthcare worker in the family was also a significant predictor of antibiotic use behaviour. Contrary to previous research, demographic variables such level of education in this study did not significantly predict intention to seek and use antibiotics [52].

To our knowledge, this is the first sufficiently validated measure which assesses factors influencing antibiotic use and misuse within a general population and the first application of the $\mathrm{TpB}$ to the prediction of antibiotic use behaviour. The measure provides an opportunity for targeted intervention programs to reduce antibiotic misuse in the general community, and may inform public policy decisions. For example, while O'Neill has observed that greater accessibility to antibiotics is associated with an increase in indiscriminate use, there are limited empirical studies exploring this relationship [3]. Our finding that $\mathrm{PBC}$ is associated with antibiotic use behaviours confirms the observations of O'Neill [3].

Our study also contributes to an understanding of the role of knowledge, and hence the value of public educational programs, on antibiotic use intentions. Previous research into this relationship is largely contradictory; whilst some indicate a relationship between lesser antibiotic knowledge and more indiscriminate antibiotic use [13, 25], others relate greater knowledge to more indiscriminate use
[53], and some do not identify a relationship between the two at all [54-56].

In our study we observed an interaction effect between knowledge and attitude/beliefs. This finding may provide evidence as to why information-intensive or educationaldriven interventions alone are not entirely efficacious or maintain long-lasting results $[57,58]$, and likely require a multi-factorial approach, targeting the range of motivating factors which contribute to antibiotic use, i.e. attitudes and beliefs, behavioural control and knowledge. As indicated by Edgar, Boyd and Palamè, behaviour change is unlikely unless motivating factors, values and subjective norm cumulatively encourage that change [57].

Consistent with the $\mathrm{TpB}$, subjective norm contributed to the prediction of antibiotic use behaviours, suggesting that antibiotic use behaviours are influenced by peers, family and community/cultural factors. This is a complex relationship given that in our study we found that the presence of family or friends working in a healthrelated field is associated with indiscriminate antibiotic use. Scaioli et al., indicated a similar finding, whereby those with a family member working in a health-related field were more likely to use non-prescribed antibiotics and keep left-over antibiotics [56]. It is likely that this relationship is associated with access to antibiotics $(\mathrm{PBC})$ and requires further investigation.

The remaining demographic variables did not significantly influence self-reported antibiotic-use behaviour. These results are not entirely surprising, given that the current literature is contradictory when examining the 
relationship between demographic variables and antibiotic use. Conflicting findings in the context of antibiotic-use behaviour are apparent for education level [53, 59, 60]; income and socioeconomic status $[29,53,61]$; gender [53, 59] and age [62, 63]. Although the reason for this inconsistency is currently unclear, it may be hypothesised that the differing geographic locations, healthcare regulations and policies of the differing countries where these studies are based may be a contributing factor, although future research is needed to investigate this. The present study, while providing a novel and important lens upon which to examine the AMR dilemma, has several limitations. First, the confusing results associated with the contribution of subjective norms requires a deeper investigation. In this study the questionnaire contained only 2 items and had the weakest internal consistency. Further research is required to uncover and input additional items which aim to target subjective norm, and which enable analysis of the relationship between $\mathrm{PCB}$ and subjective norm, is required.

Secondly, the sample size and representation is modest. This might explain why there was not a greater relationship between demographic variables and predictors of antibiotic use behaviours. A replication of this study with a larger and more representative sample would add to the value of the AUQ. Related to this, the questionnaire was distributed to an Australian sample and may not generalise to other nations or cultures. Further research is needed to determine whether the relationships identified in this study are replicated in other international samples.

Finally, the utility of the study in informing intervention programs needs to be tested. This relates in particular to the verification of antibiotic use intent, and actual antibiotic use behaviours. Application of the AUQ to a population cohort and an informed intervention based on the identified drivers of antibiotic use behaviours is required.

\section{Conclusion}

This study successfully developed and validated an original, theory driven tool which assesses factors influencing community antibiotic use and misuse. Notwithstanding the above mentioned limitations, the research highlights the pervasive influence that people-driven factors have upon antibiotic-use behaviours, likely contributing to the growth of AMR on a widespread scale. Furthermore, these findings have implications for the development of sustainable, multi-dimensional interventions that reflect the multitude of factors influencing antibiotic misuse. While AMR is a multifactorial problem requiring intervention at many levels of policy, drug discovery, and molecular biology, the role of end-point users, consumers, is a vital component of the worldwide effort to address AMR.

\section{Abbreviations}

AIC: Akaike Information Criterion; AMR: Antimicrobial resistance;

AUQ: Antibiotic Use Questionnaire; BIC: Bayesian Information Criterion; OECD: Organisation for Economic Cooperation and Development;

PBC: Perceived behavioural control; SD: Standard deviation; TNS: Taylor Nelson Sofres; TpB: Theory of Planned Behaviour; WARRA: Wollongong Antimicrobial Resistance Research Alliance; WHO: World Health Organisation

\section{Acknowledgements}

The authors would like to acknowledge the participants, for without them, this study would not have been possible.

\section{Authors' contributions}

Mitchell K. Byrne (MB) - Overall study design, oversight of data collection, review of literature, theoretical framework development, questionnaire development, interpretation of results, manuscript write up. Sebastien Miellet (SM) - Questionnaire development, statistical analysis and interpretation of results, manuscript write up. Anica McGlinn (AM) - Literature review, questionnaire development, data collection. Janaye Fish (JF) - Literature review, questionnaire development and review, manuscript write up. Shahla Meedya (ShM) - Generation of project idea, questionnaire development and review. Nina Reynolds (NM) - Questionnaire development and review. Antoine M. van Oijen (AvO) - Questionnaire development and review. All authors have read and approved this manuscript for submission.

\section{Authors' information}

Not applicable.

\section{Funding}

No funding was received for the completion of this study.

\section{Availability of data and materials}

The datasets used and/or analysed during the current study are available from the corresponding author on reasonable request.

\section{Ethics approval and consent to participate}

Ethics approval was received from the Joint University of Wollongong / Illawarra Shoalhaven Local Health District Human Research Ethics Committee, with approval reference number HE2018/330. Tacit consent was assumed by virtue of the participants completing and returning the anonymous questionnaire. This form of consent was approved by the Joint University of Wollongong / Illawarra Shoalhaven Local Health District Human Research Ethics Committee.

\section{Consent for publication}

Not applicable.

\section{Competing interests}

The authors declare that they have no competing interests.

\section{Author details}

${ }^{1}$ School of Psychology, University of Wollongong, Building 41, Northfields Ave, Wollongong, NSW 2522, Australia. ${ }^{2}$ Wollongong Antimicrobial Resistance Research Alliance (WARRA), Wollongong, New South Wales, Australia. ${ }^{3}$ Research Department, Illawarra Shoalhaven Local Health District, New South Wales, Australia. ${ }^{4}$ School of Nursing, University of Wollongong, Wollongong, New South Wales, Australia. ${ }^{5}$ Molecular Horizons Institute and School of Chemistry and Biomolecular Science, University of Wollongong, Wollongong, New South Wales, Australia. ${ }^{6}$ lllawarra Health and Medical Research Institute, Wollongong, New South Wales, Australia. ${ }^{7}$ School of Management, Operations and Marketing, University of Wollongong, Wollongong, New South Wales, Australia.

Received: 17 July 2019 Accepted: 16 October 2019

Published online: 30 October 2019

\section{References}

1. Madigan MT, Martinko JM, Dunlap PV, Clark DP. Brock biology of microorganisms 12th edn. Int Microbiol. 2008;11:65-73 https://www. researchgate.net/publication/309108432_Brock_Biology_of_ Microorganisms_12th_edn. 
2. Davies J, Davies D. Origins and evolution of antibiotic resistance. Microbiol Mol Biol Rev. 2010;74(3):417-33.

3. O'Neill, J. The review on antimicrobial resistance: tackling drug-resistant infections globally: final report and recommendations. 2016. https://amrreview.org/sites/default/files/160518_Final\%20paper_with\%20cover.pdf.

4. Fowler T, Walker D, Davies SC. The risk/benefit of predicting a postantibiotic era: is the alarm working?. Ann N Y Acad Sci 2014;1323(1):1-0.

5. Smith R, Coast J. The true cost of antimicrobial resistance. Bmj. 2013;346:f1493.

6. Alumran A, Hou XY, Sun J, Yousef AA, Hurst C. Assessing the construct validity and reliability of the parental perception on antibiotics (PAPA) scales. BMC Public Health. 2014;14(1):73.

7. Maragakis LL, Perencevich EN, Cosgrove SE. Clinical and economic burden of antimicrobial resistance. Expert Rev Anti-Infect Ther. 2008;6(5):751-63.

8. McGowan JE Jr. Economic impact of antimicrobial resistance. Emerg Infect Dis. 2001;7(2):286-92.

9. Cosgrove SE, Carmeli Y. The impact of antimicrobial resistance on health and economic outcomes. Clin Infect Dis. 2003;36(11):1433-7.

10. Weber JT, Courvalin P. An emptying quiver: antimicrobial drugs and resistance. Emerg Infect Dis. 2005;11(6):791.

11. Andersson DI, Hughes D. Antibiotic resistance and its cost: is it possible to reverse resistance? Nat Rev Microbiol. 2010;8(4):260.

12. Smith $\mathrm{RD}$, Coast J. Antimicrobial resistance: a global response. Bull World Health Organ. 2002;80:126-33.

13. Mouhieddine $T H$, Olleik Z, Itani MM, Kawtharani S, Nassar H, Hassoun R, Houmani Z, El Zein Z, Fakih R, Mortada IK, Mohsen Y. Assessing the Lebanese population for their knowledge, attitudes and practices of antibiotic usage. J Infection Public Health. 2015;8(1):20-31.

14. Buke C, Hosgor-Limoncu M, Ermertcan S, Ciceklioglu M, Tuncel M, Köse T, Eren S. Irrational use of antibiotics among university students. J Infect. 2005; 51(2):135-9.

15. World Health Organization. Antibiotic resistance: Multi-country public awareness survey. 2015. http://apps.who.int/medicinedocs/documents/ s22245en/s22245en.pdf.

16. Bosley $\mathrm{H}$, Henshall C, Appleton JV, Jackson D. A systematic review to explore influences on parental attitudes towards antibiotic prescribing in children. J Clin Nurs. 2018;27(5-6):892-905.

17. World Health Organization. WHO global strategy for containment of antimicrobial resistance. Geneva: World Health Organization; 2001. http:// www.who.int/drugresistance/WHO_Global_Strategy_English.pdf?ua=1.

18. Kandeel A, El-Shoubary W, Hicks L, Fattah M, Dooling K, Lohiniva A, Ragab O, Galal R, Talaat M. Patient attitudes and beliefs and provider practices regarding antibiotic use for acute respiratory tract infections in Minya. Egypt Antibiotics. 2014:3(4):632-44.

19. Wang $X$, Peng D, Wang W, Xu Y, Zhou X, Hesketh T. Massive misuse of antibiotics by university students in all regions of China: implications for national policy. Int J Antimicrob Agents. 2017;50(3):441-6.

20. Rather IA, Kim BC, Bajpai VK, Park YH. Self-medication and antibiotic resistance: crisis, current challenges, and prevention. Saudi J Biol Sci. 2017;24(4):808-12.

21. TNS Opinion \& Social. Antimicrobial Resistance. 2010. https://ec.europa.eu/ health/sites/health/files/antimicrobial_resistance/docs/ebs_338_en.pdf.

22. Wise R, Hart T, Cars O, Streulens M, Helmuth R, Huovinen P, Sprenger M. Antimicrobial resistance. BMJ. 1998;3(17):609-10.

23. OECD. Health at a Glance 2015: OECD Indicators 2015. http://apps.who.int/ medicinedocs/documents/s22177en/s22177en.pdf.

24. Hawkings NJ, Butler CC, Wood F. Antibiotics in the community: a typology of user behaviours. Patient Educ Couns. 2008;73(1):146-52.

25. Palmer DA, Bauchner H. Parents' and physicians' views on antibiotics. Pediatrics. 1997;99(6):E6.

26. Chan GC, Tang SF. Parental knowledge, attitudes and antibiotic use for acute upper respiratory tract infection in children attending a primary healthcare clinic in Malaysia. Singap Med J. 2006 Apr:47(4):266-70.

27. López-Vázquez P, Vázquez-Lago JM, Gonzalez-Gonzalez C, Piñeiro-Lamas M, López-Durán A, Herdeiro MT, Figueiras A. GREPHEPI group, Caamaño-Isorna F, Gestal-Otero JJ, Taracido M. development and validation of the knowledge and attitudes regarding antibiotics and resistance (KAAR-11) questionnaire for primary care physicians. J Antimicrob Chemother. 2016;71(10):2972-9.

28. Khan AA, Banu GK. Antibiotic resistance and usage-a survey on the knowledge attitude, perceptions and practices among the medical students of a southern Indian teaching hospital. J Clin Diagn Res. 2013;7(8):1613-6.

29. Roque F, Soares S, Breitenfeld L, López-Durán A, Figueiras A, Herdeiro MT. Attitudes of community pharmacists to antibiotic dispensing and microbial resistance: a qualitative study in Portugal. Int J Clin Pharm. 2013;35(3):417-24

30. Coleman CL. Examining influences of pharmacists' communication with consumers about antibiotics. Health Commun. 2003;15(1):79-99.

31. Alumran A, Hou XY, Hurst C. Validity and reliability of instruments designed to measure factors influencing the overuse of antibiotics. J Infect Public Health. 2012;5(3):221-32.

32. Eng JV, Marcus R, Hadler JL, Imhoff B, Vugia DJ, Cieslak PR, Zell E, Deneen V, McCombs KG, Zansky SM, Hawkins MA. Consumer attitudes and use of antibiotics. Emerg Infect Dis. 2003;9(9):1128-35.

33. Swinkels JM, Hilkens A, Zoche-Golob V, Krömker V, Buddiger M, Jansen J, Lam TJ. Social influences on the duration of antibiotic treatment of clinical mastitis in dairy cows. J Dairy Sci. 2015;98(4):2369-80.

34. Papoutsi C, Mattick K, Pearson M, Brennan N, Briscoe S, Wong G. Social and professional influences on antimicrobial prescribing for doctors-in-training: a realist review. J Antimicrob Chemother. 2017;72(9):2418-30.

35. Hallsworth M, Chadborn T, Sallis A, Sanders M, Berry D, Greaves F, Clements L, Davies SC. Provision of social norm feedback to high prescribers of antibiotics in general practice: a pragmatic national randomised controlled trial. Lancet. 2016;387(10029):1743-52.

36. Abasaeed A, Vlcek J, Abuelkhair M, Kubena A. Self-medication with antibiotics by the community of Abu Dhabi emirate, United Arab Emirates. J Infect Dev Ctries. 2009;3(07):491-7.

37. Chen J, Wang YM, Jie CX, Hesketh T. Ease of access to antibiotics without prescription in Chinese pharmacies: a nationwide cross-sectional study. Lancet. 2018;392:S80.

38. Erku DA, Mekuria AB, Surur AS, Gebresillassie BM. Extent of dispensing prescription-only medications without a prescription in community drug retail outlets in Addis Ababa, Ethiopia: a simulated-patient study. Drug Healthc Patient Saf. 2016;8:65.

39. Ajzen I. The theory of planned behavior. Organ Behav Hum Decis Process. 1991:50(2):179-211.

40. Armitage CJ, Conner M. Efficacy of the theory of planned behaviour: a meta-analytic review. Br J Soc Psychol. 2001;40(4):471-99.

41. Godin G, Kok $G$. The theory of planned behavior: a review of its applications to health-related behaviors. Am J Health Promot. 1996;11(2):87-98.

42. McDermott MS, Oliver M, Simnadis T, Beck EJ, Coltman T, Iverson D, Caputi P. Sharma R. The theory of planned behaviour and dietary patterns: a systematic review and meta-analysis. Prev Med. 2015;81:150-6.

43. Cooke R, Dahdah M, Norman P, French DP. How well does the theory of planned behaviour predict alcohol consumption? A systematic review and meta-analysis. Health Psychol Rev. 2016;10(2):148-67.

44. Ajzen I. Perceived behavioral control, self-efficacy, locus of control, and the theory of planned behavior ${ }^{1}$. J Appl Soc Psychol. 2002;32(4):665-83.

45. Ajzen I, Madden TJ. Prediction of goal-directed behavior: attitudes, intentions, and perceived behavioral control. J Exp Soc Psychol. 1986; 22(5):453-74

46. Sheeran P, Trafimow D, Armitage CJ. Predicting behaviour from perceived behavioural control: tests of the accuracy assumption of the theory of planned behaviour. Br J Soc Psychol. 2003;42(3):393-410

47. Conner M. Norman P. McGraw-Hill Education (UK): Predicting health behaviour; 2005

48. McEachan RR, Conner M, Taylor NJ, Lawton RJ. Prospective prediction of health-related behaviours with the theory of planned behaviour: a metaanalysis. Health Psychol Rev. 2011:5(2):97-144.

49. Crowne DP, Marlowe D. A new scale of social desirability independent of psychopathology. J Consult Psychol. 1960;24(4):349.

50. van Griethuijsen RA, van Eijck MW, Haste H, den Brok PJ, Skinner NC, Mansour N, Gencer AS, BouJaoude S. Global patterns in students' views of science and interest in science. Res Sci Educ. 2015;45(4):581-603.

51. Kimberlin CL, Winterstein AG. Validity and reliability of measurement instruments used in research. Am J Health Syst Pharm. 2008;65(23): 2276-84.

52. Pan DS, Huang JH, Lee MH, Yu Y, Mark I, Chen C, Goh EH, Jiang L, Chong JW, Leo YS, Lee TH. Knowledge, attitudes and practices towards antibiotic use in upper respiratory tract infections among patients seeking primary health care in Singapore. BMC Fam Pract. 2016;17(1):148.

53. Shehadeh M, Suaifan G, Darwish RM, Wazaify M, Zaru L, Alja'fari S. Knowledge, attitudes and behavior regarding antibiotics use and misuse among adults in the community of Jordan. A pilot study. Saudi Pharm J. 2012;20(2):125-33 
54. Huang Y, Gu J, Zhang M, Ren Z, Yang W, Chen Y, Fu Y, Chen X, Cals JW, Zhang F. Knowledge, attitude and practice of antibiotics: a questionnaire study among 2500 Chinese students. BMC Med Educ. 2013;13(1):163.

55. McNulty CA, Boyle P, Nichols T, Clappison P, Davey P. The public's attitudes to and compliance with antibiotics. J Antimicrob Chemother. 2007; 60(suppl_1):i63-8.

56. Scaioli G, Gualano MR, Gili R, Masucci S, Bert F, Siliquini R. Antibiotic use: a crosssectional survey assessing the knowledge, attitudes and practices amongst students of a school of medicine in Italy. PLoS One. 2015;10(4):e0122476.

57. Edgar T, Boyd SD, Palamé MJ. Sustainability for behaviour change in the fight against antibiotic resistance: a social marketing framework. J Antimicrob Chemother. 2008;63(2):230-7.

58. Norris P, Chamberlain K, Dew K, Gabe J, Hodgetts D, Madden H. Public beliefs about antibiotics, infection and resistance: a qualitative study. Antibiotics. 2013;2(4):465-76

59. You JH, Yau B, Choi KC, Chau CT, Huang QR, Lee SS. Public knowledge, attitudes and behavior on antibiotic use: a telephone survey in Hong Kong. Infection. 2008;36(2):153-7.

60. Pavyde E, Veikutis V, Mačiulienè A, Mačiulis V, Petrikonis K, Stankevičius E. Public knowledge, beliefs and behavior on antibiotic use and selfmedication in Lithuania. Int J Environ Res Public Health. 2015;12(6):7002-16.

61. Hofmann JO, Cetron MS, Farley MM, Baughman WS, Facklam RR, Elliott JA, Deaver KA, Breiman RF. The prevalence of drug-resistant Streptococcus pneumoniae in Atlanta. N Engl J Med. 1995;333(8):481-6.

62. Anderson A. Online health information and public knowledge, attitudes, and behaviours regarding antibiotics in the UK: multiple regression analysis of Wellcome monitor and Eurobarometer data. PLoS One. 2018;13(10):E0204878.

63. Napolitano F, Izzo MT, Di Giuseppe G, Angelillo IF. Public knowledge, attitudes, and experience regarding the use of antibiotics in Italy. PLoS One. 2013;8(12):e84177.

\section{Publisher's Note}

Springer Nature remains neutral with regard to jurisdictional claims in published maps and institutional affiliations.

Ready to submit your research? Choose BMC and benefit from:

- fast, convenient online submission

- thorough peer review by experienced researchers in your field

- rapid publication on acceptance

- support for research data, including large and complex data types

- gold Open Access which fosters wider collaboration and increased citations

- maximum visibility for your research: over $100 \mathrm{M}$ website views per year

At $\mathrm{BMC}$, research is always in progress.

Learn more biomedcentral.com/submissions 